\title{
A EDUCAÇÃO PATRIMONIAL PARA O ACESSO À INFORMAÇÃO EM ARQUIVOS E MUSEUS
}

\author{
Fernanda Frasson Martendal ${ }^{1}$ \\ Leonardo Hermes Lemos ${ }^{2}$ \\ Renata Ventura ${ }^{3}$
}

Resumo: Reflete sobre de que maneira a educação patrimonial colabora para a promoção do acesso à informação em arquivos e museus. Considera que arquivos e museus são espaços não formais de educação que, por meio de ações educativas como a educação patrimonial, podem se sobressair como instituições de acesso à informação para pesquisas e o exercício da cidadania. Evidencia que as práticas de educação patrimonial estimulam o acesso às informações nos arquivos e museus, devido ao reconhecimento de que essas instituições são custodiadoras das informações culturais e sociais.

Palavras-chave: Educação patrimonial. Acesso à informação. Arquivo. Museu.

\section{INTRODUÇÃO}

Ao se considerar a educação patrimonial como uma forma de instigar o acesso e a democratização da informação, busca-se neste trabalho, refletir de que maneira essa ação educativa colabora para o acesso à informação em arquivos e museus. Essas duas instituições são responsáveis por guardar e promover o acesso às informações produzidas, direta ou indiretamente, pela e para a sociedade, que poderá fazer uso dos documentos arquivísticos e museológicos.

Apesar de cada instituição possuir meios, métodos, objetos e objetivos distintos de atuação, é preciso ressaltar que:

Arquivos [...] e museus têm co-responsabilidade no processo de recuperação da informação, em benefício da divulgação científica, tecnológica, cultural e social, bem como do testemunho jurídico e histórico. Esses objetivos são alcançados pela aplicação de procedimentos técnicos diferentes a material de distintas origens (BELLOTTO, 2006, p. 35).

Uma alternativa para que os cidadãos desfrutem desse universo informacional, é o desenvolvimento de práticas relacionadas com a educação patrimonial. Por meio disso, os arquivos e museus podem

\footnotetext{
${ }^{1}$ Mestranda do Programa de Pós-Graduação em Ciência da Informação (PGCIN) da Universidade Federal de Santa Catarina (UFSC).

${ }^{2}$ Mestrando do Programa de Pós-Graduação em Ciência da Informação (PGCIN) da Universidade Federal de Santa Catarina (UFSC).

${ }^{3}$ Mestranda do Programa de Pós-Graduação em Ciência da Informação (PGCIN) da Universidade Federal de Santa Catarina (UFSC).
} 
ressaltar os laços que unem essas instituições ao seu acervo e também aos seus usuários. O cidadão precisa se ver como pertencente ao universo dos arquivos e museus, para compreender que ele contribui para a produção e é usuário das informações preservadas por esses ambientes.

Para explicitar tal situação, o trabalho foi divido em três partes: de início, é explorada a relação entre educação patrimonial e arquivos, mostrando perspectivas de como essa ação pode ser desenvolvida nessas instituições. A segunda parte evidencia a educação patrimonial e o museu, para o acesso à informação no âmbito do patrimônio cultural. Por fim, relaciona-se o acesso à informação à educação patrimonial, como ação educativa que contribui para a democratização da informação na sociedade. Por isso, cabe explorar o conceito de patrimônio, tanto documental como cultural.

Funari e Funari (2007) mostram que a origem do termo patrimônio para as línguas românicas (patrimonium) se referem a algo que foi passado de pai para filho, constituindo uma herança. Na língua inglesa o termo "heritage", adotado para se referir ao patrimônio, tem como significado algo que pode ser herdado. Ou seja, os arquivos e museus são instituições que preservam, comunicam e informam sobre o patrimônio, tanto cultural como documental, estabelecendo-se como espaços que o fazem de geração para geração.

O pertencimento a um grupo social cria nas pessoas o desejo de se representar e manter viva a sua história, constituindo assim o patrimônio cultural como um mediador da necessidade identitária de uma sociedade. Zanon, Magalhães e Branco (2009) analisam que o patrimônio cultural é um dos fatores que unem uma sociedade, como se fosse uma amálgama, onde os indivíduos se veem refletidos nos seus monumentos, esses, por conseguinte nos arquivos e nos museus.

Para que isso seja possível, é estabelecido pela nossa Constituição Federal de 1988, o que se caracteriza como patrimônio cultural brasileiro, sendo:

Art. 216. Constituem patrimônio cultural brasileiro os bens de natureza material e imaterial, tomados individualmente ou em conjunto, portadores de referência à identidade, à ação, à memória dos diferentes grupos formadores da sociedade brasileira, nos quais se incluem:

I - as formas de expressão;

II - os modos de criar, fazer e viver;

III - as criações científicas, artísticas e tecnológicas;

IV - as obras, objetos, documentos, edificações e demais espaços destinados ás manifestações artísticos-culturais;

$\mathrm{V}$ - os conjuntos urbanos e sítios de valor histórico, paisagístico, artístico, arqueológico, paleontológico, ecológico e científico.

Assim, vê-se que o patrimônio cultural é toda a forma de expressão de um indivíduo e/ou de um grupo social que é estabelecido tanto por sua materialidade como por sua imaterialidade, resultando num 
produto da ação humana, podendo ser uma edificação, objetos, documentos, manifestações culturais, entre outros.

Corroborando com esse posicionamento, Mansur (2016) afirma que o patrimônio cultural de um povo é estabelecido por obras que dão sentindo de existência do seu grupo social, englobando aspectos imateriais como a língua, até espaços construídos como edifícios. Ainda enfatiza que hoje existem três correntes para o patrimônio: patrimônio natural/ecológico; histórico-artístico; e o documental.

Ambos necessitam de preservação, pois estão ligados a um ecossistema comum, onde estão permeados um pelo outro, fazendo com que se sustentem sob a mesma base: o conhecimento humano sobre o mundo.

Para isso, busca-se aqui uma reflexão sobre as formas de preservação do patrimônio cultural por meio da educação patrimonial em arquivos e museus, entendendo essas instituições como preservadoras e promotoras da democratização dos bens culturais, da informação e do conhecimento.

\section{EDUCAÇÃO PATRIMONIAL E ARQUIVO}

$\mathrm{O}$ arquivo público, como entidade que preserva e busca promover o acesso à informação, é constituído por informações que se originam no decurso de funções e atividades de seu produtor. Além de informações originárias de funções e atividades relativas aos objetivos do seu produtor, também salvaguarda histórias e memórias da sociedade que é reconhecida como pesquisadora (DELGADO GÓMEZ, 2010).

Fonseca (2004) atribui a história dos arquivos públicos à constituição dos arquivos nacionais que, estruturados de maneira unitária em cada nação, congregavam toda a informação orgânica resultante dos atos administrativos, com o papel de guardá-la para a proteção e consulta limitada aos indivíduos com postos hierarquicamente superiores ao do povo.

A perspectiva dos arquivos nacionais caracterizados como instituições públicas, que direcionam seu acervo aøs diversos usuários, considera-se a partir de 1980, junto à emergência da arquivística integrada. Esta corrente de pensamento se propõe à integração do ciclo de vida dos documentos arquivísticos, aduzindo que o arquivista deva participar de todo o processo de gestão, que se inicia na criação documental e se finda com a eliminação, ou guarda permanente. Nos arquivos permanentes, o tratamento do acervo precisa englobar a promoção do acesso e difusão da informação orientados ao público.

Como propõe Santos (2007), o arquivo e o arquivista devem se unir, a fim de que o profissional parta à diante com ações que fomentem a divulgação informacional e do espaço do arquivo, aproximando 
seus públicos frequentes e potenciais, estejam as informações disponibilizadas em ambiente físico, ou digital. Esta aproximação vai ao encontro da gestão informacional arquivística, que se direciona à interação afinada entre profissional arquivista, informação arquivística e público.

Para Arquivo Nacional (2005) e Ortega (2013), o acesso à informação contempla a chegada do público até o documento e sua utilização, processos que são diferentes, pois não dependem somente da disponibilização da informação, mas da criação de meios a partir dos quais o público possa se familiarizar com ela, criando autonomia na pesquisa dentro do arquivo e apropriando-se deste espaço, bem como de sua história. Mencionada utilização pode estar familiarizada com práticas educativas dentro de unidades de informação, pois o ato de ensinar a utilizar os recursos informacionais (como acervos arquivísticos e museológicos) demanda que o profissional domine habilidades e valores inerentes a sua profissão, bem como disponha de prática didática, para poder tornar os usuários dessas informações, também competentes em informação.

A competência em informação, para Vitorino e Piantola (2011), reúne um conjunto de habilidades e valores que pode ser desenvolvido ao longo da vida, cuja prática se dá de diferentes maneiras, pois cada indivíduo dispõe de características distintas entre si e entre seus grupos. Para os profissionais da informação, atuando eles em quaisquer tipos de unidades de informação, as recomendações giram em torno do desenvolvimento de habilidades técnicas, estéticas, éticas e políticas relacionadas a seu cotidiano laboral, focando em ações como a conservação documental, sua descrição e organização física, por exemplo. Já para os usuários das informações, estas recomendações são voltadas à utilização dos acervos, enfatizando a observância, como exemplo, à preservação dos suportes e conteúdos pesquisáveis e à ética em relação à classificação de sigilo no momento da pesquisa.

Algumas ações a fim de viabilizar o acesso à informação pública podem ser tomadas como rotinas em ambientes de arquivos e de escolas, como assim relatam Parrela e Koyama (2016) e Aldabalde (2012), que propõem a educação patrimonial e a utilização de documentos arquivísticos aliada a atividades escolares, como subsídios para a aproximação de usuários aos arquivos e a seus acervos.

A perspectiva de acesso à informação, no escopo da Arquivologia, pode ser identificada como inerente à difusão da informação arquivística que, como comenta Charbonneau (2008), localiza-se dentre as sete funções da gestão documental arquivística e se ocupa da divulgação orientada de acervos, da viabilização de seu acesso e de sua utilização. Estas ações, para o autor, estão relacionadas com cada uma das seis funções que a acompanham, pois durante todo o seu ciclo vital, as informações arquivísticas passam por diferentes classificações de acesso ao público (dividido entre público interno e externo a um 
arquivo).

As características distintas inerentes a cada usuário, relacionadas também ao modo com que realizam atividades de pesquisa, fazem com que o acesso aos arquivos demande deste local mais do que um ambiente que se proponha a ser cultural, mas que seja, sobretudo, um lugar de formação (ALDABALDE, 2012). O indivíduo que adentra um arquivo, ou acessa um sistema de informação arquivístico, deve familiarizar-se com as ações que precisa realizar, para que encontre e utilize a informação buscada, o que demanda iniciativas a partir dos arquivistas, pois eles cumprem papel de intermediários entre a informação e o público que se aproxima do arquivo (PARRELA; KOYAMA, 2016).

Quando o arquivista se volta às atividades de gestão, realizando-a de maneira ética, condizente à legislação arquivística e considerando o público como sujeito ativo no cotidiano do arquivo, se aproxima às características de intermediário na emissão/recepção da informação. Dessa forma, abre seus horizontes tanto à informação pública, preservando-a, quanto ao público, orientando-o a acessar e a utilizar conscientemente as informações. O quadro 1 expõe as características inerentes à tríade arquivista, informação arquivística e público.

Quadro 1 - Tríade profissional arquivista, informação orgânica e público

\begin{tabular}{|c|c|c|}
\hline $\begin{array}{c}\text { PROFISSIONAL } \\
\text { ARQUIVISTA }\end{array}$ & $\begin{array}{c}\text { INFORMAÇÃO } \\
\text { ORGÂNICA }\end{array}$ & PÚBLICO \\
\hline Gestor & Gerenciada & Receptor ativo \\
\hline Emissor & Representada & Utilizador \\
\hline Referência & Comunicada & Sujeito que rememora \\
\hline Mediador & & \\
\hline
\end{tabular}

Fonte: Lousada (2015).

Quando Delgado Gómez (2010) aduz que a sociedade está vinculada ao arquivo, infere que a informação pública custodiada por arquivos é composta pela memória social, que se encontra armazenada nessas instituições, para a posteridade. A partir de resquícios de memórias individuais sobre ações cotidianas, registradas em um documento, a memória coletiva também se insere no momento da pesquisa, 
o que faz com que o público, ao ter contato com estas informações, desenvolva sensações de pertencimento em relação às histórias apresentadas.

Desta maneira, como iniciativas para aproximação do público ao arquivo, estão as ações educativas, dentre as quais se destaca a educação patrimonial, que é identificada como uma ação ampla, que engloba profissional da informação, acervo e público (HORTA; GRUNBERG; MONTEIRO, 1999). Este tipo de ação vem sendo observado como o pontapé para as ações arquivísticas relacionadas à difusão da informação.

Estar acessível é partir para ações em ambientes distintos, físicos ou eletrônicos, para que o público participe das distintas esferas em que as informações podem estar inseridas, seja pesquisando-as por um catálogo online, com interface audiovisual, ou adentrando a uma sala de pesquisas de um edifício de arquivo, com catálogos disponíveis em braille. Lousada (2015) aponta que as atribuições do arquivista serão delineadas também conforme a resposta do público, proporcionando ações para tornar o ambiente aprazível para a pesquisa, dotar de visibilidade o arquivo como instituição e focar no papel do arquivista para com as informações e o público, num processo de ensino-aprendizagem.

A cultura e a educação em arquivos como processos irmãos da difusão da informação arquivística são "[...] uma prática, de certo modo, antiga nos arquivos públicos, mas com pouco espaço para reflexão sobre suas experiências, métodos e referenciais teóricos" (PARRELA; KOYAMA, 2016, p. 05).

Iniciativas no sentido de propor práticas educativas, distinguem o arquivo como espaço de educação não formal, caracterizada por Gohn (2009, p. 31) como processo desenvolvido “[...] usualmente extramuros escolares [...]. [O processo de educação não formal está] [...] no centro das atividades [...], especialmente no campo das Artes, Educação e Cultura". Espaços como este suscitam aprendizagem diferenciada, pois estará ambientada em outros lugares que não o formal, que se dará a partir, também, de recursos diferentes dos comumente utilizados, pois ao invés de quadro negro e giz, haverá documentos, luvas e máscaras, por exemplo.

Em arquivos, a educação patrimonial encontra-se como prática educativa que consegue unir profissionais, informações e público. Definida por Horta, Grunberg e Monteiro (1999), a educação patrimonial propõe que o público perceba os espaços patrimoniais, neste caso o arquivo e os itens documentais que o compõem, como pertencentes a conjuntos que se referem a aspectos da vida pública, patrimônio de toda a sociedade. Consiste esta ação educativa em

[...] um instrumento de "alfabetização cultural" que possibilita ao indivíduo fazer a leitura do mundo que o rodeia, levando-o à compreensão do universo sociocultural e da trajetória histórico-temporal em que está inserido. Este processo leva ao reforço da auto- 
estima dos indivíduos e comunidades e à valorização da cultura brasileira, compreendida como múltipla e plural (HORTA; GRUNBERG; MONTEIRO, 1999, p. 04, grifo das autoras).

Para a prática da educação patrimonial "como estratégia fundamental do exercício da cidadania" (MANCEBO-CARNEIRO; GOMES; PINTO, 2016, p. 47), o arquivista deve estar atento ao que concebe como patrimônio dentro do arquivo, pois é desejada a imparcialidade diante das informações orgânicas, além do inter-relacionamento informacional, que consiste na contextualização entre itens documentais.

A partir destas ações, o arquivo não se torna somente lugar de pesquisa, mas espaço de prazer e lazer, como afirmam Parrela e Koyama (2016, p. 07):

$\mathrm{O}$ arquivista, o educador e/ou historiador [...] podem estimular abordagens e usos distintos do arquivo, de modo democrático, garantindo, ao mesmo tempo, o acesso aos acervos documentais pelo seu valor de prova e testemunho, como também para fruição e a produção de conhecimento educacional, sociocultural e acadêmico.

A educação patrimonial, nesse sentido, pode ser observada em distintos espaços de informação, para os quais Horta, Grunberg e Monteiro (1999) propõem os passos a serem seguidos quando da implementação de um programa de educação patrimonial em quaisquer destas instituições:

Figura 1 - Aplicação da metodologia de educação patrimonial

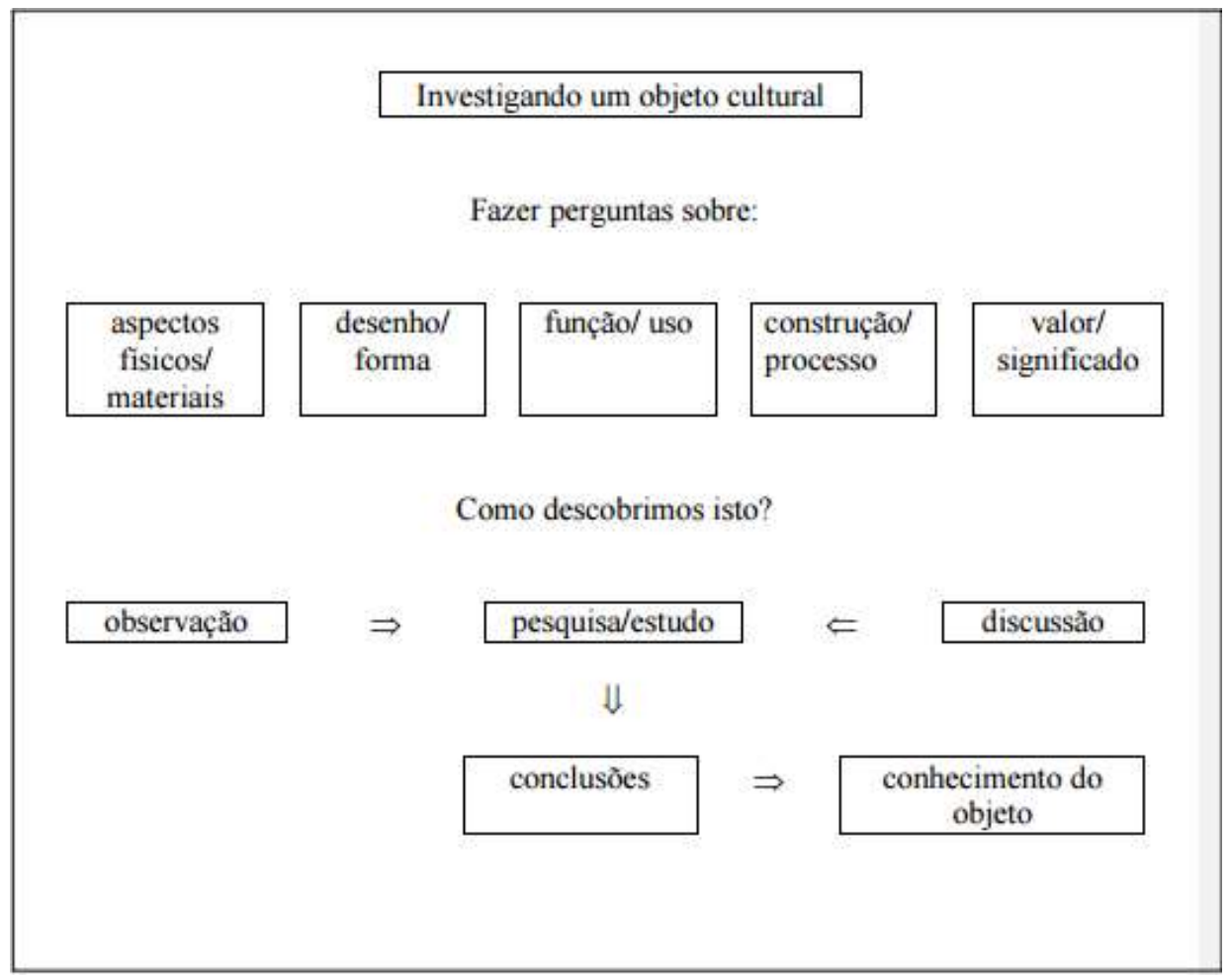

Fonte: Horta, Grunberg e Monteiro (1999, p. 08). 
Os procedimentos citados na figura 1 podem ser incorporados tanto por arquivos como por museus, com o principal objetivo de democratizar o acesso à informação pública, de maneira didática e fazendo destes espaços de educação, lugares de compartilhamento de ideias. Para a atuação do arquivista no espaço de formação que é o arquivo são demandadas as habilidades técnicas relacionadas a procedimentos junto ao acervo e também às percepções sobre o público envolvido, para que o arquivo seja evidenciado como lugar de ensino-aprendizagem.

\section{EDUCAÇÃO PATRIMONIAL E MUSEU}

As instituições museológicas ao longo do seu desenvolvimento passaram por grandes mudanças na sua base fundadora e no seu papel social. Assim, os museus (antes lugares de depósito) hoje são um local de fruição e comunicação da informação e do conhecimento.

Ao fazer uma breve retrospectiva sobre a constituição histórica e social dos museus Suano (1986), mostra como as instituições se modificaram ao passar do tempo. Desde o mouseion, na Grécia, até a formação dos museus modernos com a revolução francesa, o objetivo desses espaços estava centrado na exposição dos objetos.

Com o desenvolvimento da sociedade, os museus passaram a ser instituições fundamentais para o aprendizado e educação fora das instituições de ensino tradicionais como, escolas e universidades. Conforme a Lei ${ }^{\circ} 11.904$, de 14 de janeiro de 2009, que estabelece o Estatuto de Museus, em seu artigo $1^{\circ}$ fica posto que:

Consideram-se museus, para os efeitos desta Lei, as instituições sem fins lucrativos que conservam, investigam, comunicam, interpretam e expõem, para fins de preservação, estudo, pesquisa, educação, contemplação e turismo, conjuntos e coleções de valor histórico, artístico, científico, técnico ou de qualquer outra natureza cultural, abertas ao público, a serviço da sociedade e de seu desenvolvimento (BRASIL, 2009).

Nota-se que além dos museus manterem seu caráter de guarda e exposição, passaram a ter a educação como um dos seus eixos basilares, o que faz refletir sobre como os museus utilizam dos serviços educacionais e, por isso, destaca-se aqui a educação patrimonial, como meio de acesso à informação.

Santos (2008) mostra que o conceito de museu para muitos, principalmente no âmbito escolar (aluno e professor), ainda é sinônimo de local para guarda de coisas velhas e que o patrimônio cultural é uma referência do passado ao qual não se sentem pertencidos. Ou seja, trabalhar com a memória e principalmente com o patrimônio cultural se torna algo complexo, pois esses sujeitos são passivos no 
processo de ensino-aprendizagem em relação ao patrimônio cultural, já que não está refletido em suas vidas pessoais.

Em contraponto, Dias e Soares (2007) expõem que existe uma necessidade prévia em conhecer os mundos de cada pessoa que tiver contato com algum tipo de ação educativa e que isso acarreta na reflexão dos motivos de aprender e ensinar sobre o patrimônio cultural.

Por meio da educação patrimonial, Funari e Funari (2007) colocam que essa prática não se restringe apenas à sala de aula. Logo, pode-se referenciar o museu como uma instituição que colabora com o processo de ensino-aprendizagem, consequentemente informa e auxilia na produção de conhecimento.

Dias e Soares (2007) afirmam que a educação patrimonial é uma das formas de ensinar a partir dos bens culturais a valorizar e conservar esses bens para a posterioridade. Assim, ao trabalhar com o patrimônio cultural, disponibilizando às pessoas informações básicas para conhecerem o seu meio e saber como sua sociedade foi constituída, o processo de democratização e acesso à informação começa a dar resultado.

O objetivo da educação em museus, assim como da educação em um sentido amplo, é oferecer possibilidades para a comunicação, informação, aprendizado, relação dialética e dialógica educando/educador, construção de cidadania e o entendimento do que seja identidade (STUDART et al., 2004)

Por meio da educação patrimonial, é estabelecida uma ligação direta entre a instituição museológica e o seu público, onde essa ação não isolada possibilita às pessoas terem maior acesso e conhecimento ao patrimônio cultural, sendo um meio determinante para o acesso à informação a todos.

No entanto, o acesso à informação mediante a educação patrimonial, só é possível se a população se reconhece e se vê pertencida por aquele patrimônio. Por isso é necessário que as pessoas escolham as formas com que estarão representadas, para que possam por meio deles também valorizar o patrimônio cultural já existente (DIAS; SOARES, 2007).

Ao mesmo tempo em que existe esse trabalho de educação patrimonial, Santos (2008) enfatiza que a análise do patrimônio cultural deve ter um cunho educativo e não instrutivo. Ou seja, deve haver reflexão sobre o passado, e no que isso interfere no presente, como esses processos que aconteceram antes influenciaram e determinaram padrões em nossa sociedade atual (FREIRE, 2000).

A educação patrimonial no âmbito museal está diretamente ligada ao acesso à informação em relação à preservação do patrimônio cultural, e como as pessoas compreendem sua identidade na sociedade da informação. 


\section{ACESSO À INFORMAÇÃO}

O acesso informacional traz consigo desde as questões relacionadas com o sigilo e a restrição do acesso, até indagações inerentes à ampla interação com os conteúdos informativos. De qualquer forma, o contexto que envolve o acesso à informação se insere nos trabalhos e estudos dos profissionais da informação, que não se dedicam exclusivamente ao tratamento informacional, mas também com o desenvolvimento social.

A relevância dos estudos sobre a informação está relacionada com o próprio desenvolvimento social. Para a sociedade da informação o cuidado com esse tipo de insumo a afeta de forma mais incisiva, do que, por exemplo, para a sociedade industrial. Com relação a isso, Werthein (2000, p. 71) discorre que:

A expressão "sociedade da informação" passou a ser utilizada, nos últimos anos desse século, como substituto para o conceito complexo de "sociedade pós-industrial" e como forma de transmitir o conteúdo específico do "novo paradigma técnico-econômico". A realidade que os conceitos das ciências sociais procuram expressar refere-se às transformações técnicas, organizacionais e administrativas que têm como "fator-chave" não mais os insumos baratos de energia - como na sociedade industrial - mas os insumos baratos de informação propiciados pelos avanços tecnológicos na microeletrônica e telecomunicações.

Informação perpassa diversos segmentos e contextos sociais, ratificando a principal característica de uma sociedade que a utiliza de forma intensiva. Sendo assim, os diferentes tipos, fontes, suportes e meios para transmissão da informação passam a ter valor significativo para a sociedade. Abandona-se o entendimento de que informação é somente aquela disseminada pelos meios de comunicação.

Além disso, insere-se nas discussões relacionadas a essa temática, o acesso à informação. Para que uma sociedade, caracterizada pelo reconhecimento do poder informativo, possa se desenvolver é preciso que o acesso à informação seja uma premissa básica. No entanto, a promoção do acesso informacional, pode ocorrer de forma que esteja restrito às variáveis que não corroboram com o interesse coletivo. Podese exemplificar isso, por meio de uma situação onde determinada instituição de informação restringe o acesso a determinadas informações devido os interesses particulares.

Diante dessa possível realidade, recai para o cidadão, enquanto usuário da informação, a aptidão de selecionar e relacionar diferentes fontes e instituições informacionais para suprir suas carências. Ter um comportamento proativo na pesquisa, acesso e análise das informações permite que o usuário da informação faça suas próprias ponderações e seleções dos materiais que lhe são úteis. Sendo assim:

Permitir a todos o acesso a informação é crucial para o desenvolvimento individual e coletivo do cidadão, e o caminho a ser percorrido para capacitar o cidadão ao uso crítico 
da informação é uma tarefa que as escolas, as universidades e todos os tipos de bibliotecas, públicas, universitárias e outras, devem assumir. Preparar os cidadãos para a sociedade da informação constitui tarefa prioritária para o governo, as organizações e seus profissionais (TARAPANOFF; SUAIDEN; OLIVEIRA, 2002, p. 3).

Dentro desse contexto que engloba informação e seus usuários, estão os profissionais da informação, que vão trabalhar com o intuito de otimizar a recuperação, o acesso e o uso informacional. O trabalho desses profissionais, além de auxiliá-los nas suas atividades, também procurará a consonância com o perfil e as necessidades dos usuários. Assim, além da competência necessária ao trabalho com as novas tecnologias, destaca-se nos profissionais da informação a aptidão para intermediar a relação entre o contexto social e o informacional (FREIRE, 2006).

As habilidades e a competência com a informação serão desenvolvidas conforme o contexto em que está inserido o profissional da informação, por exemplo, em arquivos e museus. Essas duas instituições trabalham com informações que são produzidas pela sociedade e de interesse dessa mesma, ou seja, “[...] arquivos, museus, universidades, escolas, entre outras são também responsáveis pela transmissão e pelo provimento dos saberes produzidos no percurso da história da humanidade" (CARVALHO; KANISKI, 2000, p. 36, grifo nosso). Tendo em vista a afirmativa anterior, conclui-se que os arquivos e museus são instituições que têm por objetivo a interação constante com a sociedade para promoção da educação patrimonial.

Os objetos museológicos e os acervos arquivísticos são fontes de informações que podem e devem ser utilizadas pelos cidadãos. Isso exige que as instituições responsáveis por essas informações estejam aptas para a aproximação com os seus usuários, e o atendimento das necessidades informacionais. A sociedade precisa reconhecer que os arquivos e os museus são patrimônios documentais e culturais, e por isso são fontes de informação que constituem a identidade social.

Além de uma mudança de postura por parte dos cidadãos, o acesso informacional depende também da transformação institucional nos arquivos e museus. Araújo (2014) expõe que para a perspectiva contemporânea da Arquivologia e Museologia houve uma expansão das preocupações dessas instituições, englobando a inserção no contexto social; cuidados com os seus usuários; atenção aos desdobramentos dos trabalhos arquivísticos e museológicos nos seus acervos, além das implicações do próprio acervo. Essas duas instituições deixam de se restringir ao armazenamento dos acervos e se inserem no universo informacional.

Sob essa perspectiva social e cultural dos arquivos e museus com relação ao acesso à informação é necessário compreender que: 
A cultura funcionaria como uma memória que ao conservar e reproduzir artefatos simbólicos e materiais de geração em geração, torna-se a depositária da informação social. [...]. Dessa forma, a socialização da cultura (linguagem, estética, visão de mundo, valores, costumes) assume papel relevante para a democratização do acesso e uso da informação (FREIRE, 2006, p. 59).

Democratizar o acesso à cultura é uma das atividades desenvolvidas pelas instituições arquivísticas e museológicas, tendo em vista que esses tipos de informação podem ser custodiados por elas. Preservando essas informações, obtém-se também a manutenção da identidade social, pois por meio desses acervos os cidadãos podem refletir sua história e decidir sobre o presente.

Uma forma de auxiliar esse processo de interação entre instituições e usuários, pode ser o uso das novas tecnologias, no entanto, isso exige que os cidadãos possuam um arcabouço educacional e cultural para utilização desses recursos (CARVALHO; KANISKI, 2000). Isso demonstra que o acesso à informação nos arquivos e museus está relacionado com outras questões sociais que impactam de forma direta o reconhecimento e utilização dessas instituições.

A informação é um instrumento de poder e até mesmo de cidadania, por isso:

[...] só pode ser considerada como instrumento de mudança e transformação social se for colocada à disposição dos cidadãos através de serviços públicos fornecidos pelo Estado, visto se tratar de um direito de cidadania. $\mathrm{O}$ acesso à informação é fundamental à participação dos indivíduos nos processos decisórios, sendo elemento fundamental para que possam fazer suas escolhas e opções. Esta é uma das principais formas que possibilitam o exercício pleno de seus direitos de cidadania [...] (CABRAL, 2007, p. 4546).

O exercício da cidadania se faz também com o acesso informacional, pois assim é possível acompanhar atos e decisões em diversos segmentos sociais. Ampliar as opções das fontes de informação e promover a independência no processo informativo são ações que impulsionam o desenvolvimento social.

Arquivos e museus fazem parte da atual sociedade da informação, promovendo o acesso e difusão dos seus acervos. Por meio da educação patrimonial os cidadãos identificam nessas instituições a sua função social. Assim, a fusão das atividades de acesso à informação juntamente com a educação patrimonial, além de auxiliar os arquivos e museus, também estende seus benefícios à sociedade.

\section{CONSIDERAÇÕES FINAIS}

Os arquivos e museus são instituições há bastante tempo presentes no contexto social, no entanto, nem sempre receberam o reconhecimento necessário sobre suas funções. Com a difusão da educação patrimonial e do acesso à informação, ganham evidência esses tipos de instituições voltadas à preservação 
das informações inerentes à sociedade.

A educação patrimonial se apresenta como forma de aproximar os arquivos e museus dos seus usuários, pois demonstra que as informações custodiadas por eles não são alheias à realidade social. Além disso, esse tipo de prática se baseia no reconhecimento do perfil desses usuários, fazendo com que sejam desenvolvidos serviços, de acordo com as necessidades e/ou anseios deles.

As vertentes mais recentes da Arquivologia e Museologia procuram abandonar a exclusividade da guarda do acervo, para se inserirem também do tratamento informacional. Isso vai ao encontro das demandas da sociedade, em que a difusão da informação é uma atividade que contribui para a inserção do cidadão em diversos ambientes, ou seja, permitindo o exercício da sua cidadania.

Essa inserção engloba também os ambientes referentes os arquivos e museus, com o intuito de que o cidadão adquira familiaridade com eles. Utilizá-los como espaços de educação não formal, nos quais serve-se de recursos diferenciados, estimula a presença do público nessas instituições e os usos das suas informações. A partir disso, pode-se instigar a preservação dos ambientes arquivísticos e museológicos, pois o cidadão, enquanto usuário, reconhece o poder informativo dessas instituições.

Os arquivos e museus são formados por meio das atividades desenvolvidas pela sociedade, logo, promovem a preservação da cultura e da identidade social. Assim, a educação patrimonial nessas instituições, contribui para o reconhecimento social delas como custodiadoras e promotoras do acesso às informações culturais e sociais. Nesse cenário, o cidadão tem ao seu alcance mais uma ferramenta para exercício da sua cidadania, ou seja, as informações arquivísticas e museológicas.

\section{REFERÊNCIAS}

\section{ALBERCH I FUGUERAS, Ramón. Los archivos, entre la memoria histórica y la sociedad del conocimiento. Barcelona: Editorial UOC, 2003. 221 p.}

ALDABALDE, Taiguara Villela. Arquivologia e pedagogia arquivística: Bases para uma habilitação que ensine o arquivista a educar. In: MARIZ, Anna Carla Almeida; JARDIM, José Maria; SILVA, Sérgio Conde de Albite (Org.). Novas dimensões da pesquisa e do ensino da Arquivologia no Brasil. Rio de Janeiro: Móbile, 2012. p. 198-212.

ARQUIVO NACIONAL (Brasil). Dicionário brasileiro de terminologia arquivística. Rio de Janeiro: Arquivo Nacional, 2005. 232p.

\section{ARAÚJO, Carlos Alberto Ávila. Arquivologia, Biblioteconomia, Museologia e Ciência da Informação: o diálogo possível. Brasília: Briquet de Lemos, São Paulo: Associação Brasileira de Profissionais da Informação, 2014.}


BELLOTTO, Heloísa Liberalli. Arquivos Permanentes: tratamento documental. 4. ed. Rio de Janeiro: FGV, 2006.

BRASIL. Decreto $n^{\circ} 5.296$, de 02 de dezembro de 2004. Regulamenta as Leis $n^{\text {os }} 10.048$, de 8 de novembro de 2000, que dá prioridade de atendimento às pessoas que especifica, e 10.098, de 19 de dezembro de 2000, que estabelece normas gerais e critérios básicos para a promoção da acessibilidade das pessoas portadoras de deficiência ou com mobilidade reduzida, e dá outras providências. Diário Oficial da República Federativa do Brasil. Brasília, DF, 02 dez. 2004. Disponível em:

<http://www.planalto.gov.br/ccivil_03/_ato2004-2006/2004/decreto/d5296.htm>. Acesso em: 26 dez. 2016.

Lei 11.904, de 14 de janeiro de 2009. Regulamenta e Institui Estatuto de Museus e dá outras Providências. Diário Oficial da República Federativa do Brasil. Brasília, DF, 15 jan. 2009. Disponível em: <http://pesquisa.in.gov.br/imprensa/jsp/visualiza/index.jsp?jornal=1\&pagina=1\&data=15/01/2009>. Acesso em: 21 mar. 2017

CABRAL, Ana Maria Rezende. A Ciência da Informação, a cultura e a sociedade informacional. In: REIS, Alcenir; CABRAL, Ana Maria Rezende (Org.). Informação, cultura e sociedade: interlocuções e perspectivas. Belo Horizonte: Novatus, 2007. p. 29-48.

CARVALHO, Isabel Cristina Louzada; KANISKI, Ana Lúcia. A sociedade do conhecimento e o acesso à informação: para que e para quem? Ciência da Informação, Brasília, v. 29, n. 3, p. 33-39, set./dez. 2000. Disponível em: <http://revista.ibict.br/ciinf/article/view/871/905>. Acesso em: 20 mar. 2017.

CHARBONNEAU, Normand. La diffusion. In: COUTURE, Carol et al. Les Fonctions de l'Archivistique Contemporaine. Québec: Presses de L'université du Québec, 2008. Cap. 8. p. 373-428.

DELGADO GÓMEZ, Alejandro. Los archivos como construcción social. In: DELGADO GÓMEZ, Alejandro; CRUZ MUNDET, José Ramón. El archivo como construcción social. Las Palmas: Anroart, 2010. p. 7-111.

DIAS, Guilherme; SOARES, André Luis Ramos. Educação Patrimonial e Educação Popular: um viés possível. In: SOARES, André Luis Ramos (Org.). Educação Patrimonial: teoria e prática. Santa Maria: UFSM, 2007. Cap. 4. p. 65-78.

FONSECA, Maria Odila Kahl. Arquivologia e Ciência da Informação: (re)definição de marcos interdisciplinares. 2004. 181 f. Tese (Doutorado) - Curso de Doutorado em Ciência da Informação, Universidade Federal do Rio de Janeiro, Rio de Janeiro, 2004.

FREIRE, Isa Maria. Acesso à informação e identidade cultural: entre o global e o local. Ciência da Informação, Brasília, v. 35, n. 2, p. 58-67, maio/ago. 2006. Disponível em:

<http://revista.ibict.br/ciinf/article/view/1141/1299>. Acesso em: 21 mar. 2017.

FREIRE, Paulo. Pedagogia da indagação: cartas pedagógicas e outros escritos. São Paulo: Ed. Unesp, 2000.

FUNARI, Pedro Paulo; FUNARI, Raquel dos Santos. Educação Patrimonial: teoria e prática. In: 
SOARES, André Luis Ramos (Org.). Educação Patrimonial: teoria e prática. Santa Maria: UFSM, 2007. Cap. 1. p. 11-23.

GOHN, Maria da Gloria. Educação não-formal, educador(a) social e projetos sociais de inclusão social. Meta: avaliação, Rio de Janeiro, v. 1, n. 1, p. 28-43, jan./abr. 2009. Disponível em: <http://revistas.cesgranrio.org.br/index.php/metaavaliacao/article/view/1>. Acesso em: 20 mar. 2017.

HORTA, Maria de Lourdes Parreira; GRUNBERG, Evelina; MONTEIRO, Adriane Queiroz. Guia básico de educação patrimonial. Brasília: IPHAN: Museu Imperial, 1999. Disponível em: <http://portal.iphan.gov.br/uploads/temp/guia_educacao_patrimonial.pdf.pdf>. Acesso em: 14 mar. 2017.

LOUSADA, Mariana. A mediação da informação na Teoria Arquivística. Tese (Doutorado em Ciência da Informação) - Universidade Estadual Paulista, Faculdade de Filosofia e Ciências, Marília, 2015.

MANCEBO-CARNEIRO, Tarsila; GOMES, Priscila Ribeiro; PINTO, Luíza Angélica Lisboa. Educação patrimonial: conversando sobre patrimônio e cidadania no Instituto Superior de Educação do Estado do Rio de Janeiro. In: PARRELA, Ivana Denise; KOYAMA, Adriana Carvalho (Org.). Simpósio temático Arquivos \& Educação. Belo Horizonte: Escola de Ciência da Informação, Programa de Pós-graduação em Ciência da Informação, 2016. 144 p. p. 44-57. Disponível em: <https://drive.google.com/file/d/0BBESfxHN3OgVzlEOUk5Q29KNjg/view>. Acesso em: 14 mar. 2017.

ORTEGA, Cristina Dotta. Ciência da informação: do objetivo ao objeto. In: RENDÓN ROJAS, Miguel Ángel. El objeto de estudio de la bibliotecología/documentación/ciencia de la información: propuestas, discusión, análisis y elementos comunes. Cidade do México: UNAM, Instituto de Investigaciones Bibliotecológicas y de la Información, 2013. 295p. p. 151-177.

PARRELA, Ivana Denise; KOYAMA, Adriana Carvalho (Org.). Simpósio temático Arquivos \& Educação. Belo Horizonte: Escola de Ciência da Informação, Programa de Pós-graduação em Ciência da Informação, 2016. 144 p. Disponível em: <https://drive.google.com/file/d/0B-

BESfxHN3OgVzlEOUk5Q29KNjg/view>. Acesso em: 14 mar. 2017.

SANTOS, Maria Célia Teixeira Moura. Encontros Museológicos: reflexões sobre a museologia, a educação e o museu. Rio de Janeiro: Minc, 2008. 256 p.

SANTOS, Vanderlei Batista dos. Arquivística: temas contemporâneos. Distrito Federal: SENAC, 2007.

STUDART, Denise Coelho; et al. Educação em museus: produto ou processo? MUSAS: Revista Brasileira de Museus e Museologia, Rio de Janeiro, n. 1, p. 34-40, 2004.

SUANO, Marlene. O que é museu? São Paulo: Brasiliense, 1986.

TANODI, Aurelio. The status of archivists in relation to other information professionals in the public service in Latin America. Paris: UNESCO, 1985.

TARAPANOFF, Kira; SUAIDEN, Emir; OLIVEIRA, Cecília Leite. Funções sociais e oportunidades para profissionais da informação. DataGramaZero: Revista de Ciência da Informação, Rio de Janeiro, v. 
3, n. 5, p. 1-13, out./2002. Disponível em:

$<$ http://repositorio.unb.br/bitstream/10482/884/1/ARTIGO_FuncoesSociaisOportunidadesProfissionais.p df>. Acesso em: 20 mar. 2017.

VÁZQUEZ MURILLO, Manuel. Administración de documentos y archivos: planteos para el siglo XXI. Buenos Aires: Alfagrama, 2008, 176 p.

VITORINO, Elizete Vieira; PIANTOLA, Daniela. Dimensões da competência informacional (2). Ciência da Informação, Brasília, v. 40, n. 1, p. 99-110, jan. /abr. 2011. Disponível em:

<http://revista.ibict.br/ciinf/article/view/1328/1507>. Acesso em: 20 mar. 2017.

WERTHEIN, Jorge. A sociedade da informação e seus desafios. Ciência da Informação, Brasília, v. 29, n. 2, p. 71-77, maio/ago. 2000. Disponível em: 〈http://revista.ibict.br/ciinf/article/view/889/924>. Acesso em: 20 mar. 2017.

\title{
THE PATRIMONIAL EDUCATION FOR ACCESS TO INFORMATION IN ARCHIVES AND
}

\section{MUSEUMS}

\begin{abstract}
This article reflects about how the patrimonial education helps in the information access promotion at archives and museums. It considers that archives and museums are non-formal spaces of teaching-learning that, through educatifs actions like the patrimonial education, can stand out as institutions for access to research information and for the exercise of the citizenship. It evidences that the practices of patrimonial education encourage the information access at archives and museums, due to the recognition that these institutions are custodians of the cultural and social informations.
\end{abstract}

Keywords: Patrimonial education. Information access. Archive. Museum.

\section{FERNANDA FRASSON MARTENDAL}

Mestranda do Programa de Pós-Graduação em Ciência da Informação (PGCIN) da Universidade Federal de Santa Catarina (UFSC). Bacharel em Arquivologia pela mesma universidade. E-mail: fernanda.martendal@hotmail.com

\section{LEONARDO HERMES LEMOS}

Mestrando do Programa de Pós-Graduação em Ciência da Informação (PGCIN) da Universidade Federal de Santa Catarina (UFSC). Bacharel em Museologia pela mesma universidade. E-mail: leohermeslemos29@gmail.com

\section{RENATA VENTURA}

Mestranda do Programa de Pós-Graduação em Ciência da Informação (PGCIN) da Universidade Federal de Santa Catarina (UFSC). Bacharel em Arquivologia pela mesma universidade. E-mail: ventura_r@hotmail.com

\section{RECEBIDO EM: 24-03-2017}

